\title{
Implementing Database Methods for Increasing the Performance of Intelligent CCTV
}

\author{
Yong Wan Ju and Seung Jai Yi \\ KISA (Korea Internet \& Security Agency) \\ ywju@kisa.or.kr,king7@kisa.or.kr
}

\begin{abstract}
This paper is written for intelligent CCTV (Closed-Circuit Television) which has been important in the aspect of industrial value and social security these days. Because the intelligent CCTV can identify behavior and object automatically, and it has been used extensively. With spread use, the performance of the intelligent CCTV has been important. But a standard method to measure the performance of the intelligent CCTV is absence, therefore this paper is described about methods for implementing and measuring of the intelligent CCTV performance.
\end{abstract}

Keywords: intelligent CCTV, intelligent CCTV database, intelligent CCTV performance

\section{Introduction}

The industry and technology of CCTV (Closed-Circuit Television) has been increased and moved to an important position for over decades, because terrors, anti-social behaviors and arsons have been happened rapidly.

After the advent of CCTV in 1950s, technology transforming into digital files which can be stored in hard drive has been developed to see the files by Internet. Recently, the CCTV converged with network and IT technologies has been progressed to watch behaviors of objects and human and identify them automatically. And the CCTV namely intelligent CCTV has applied to multi-area.

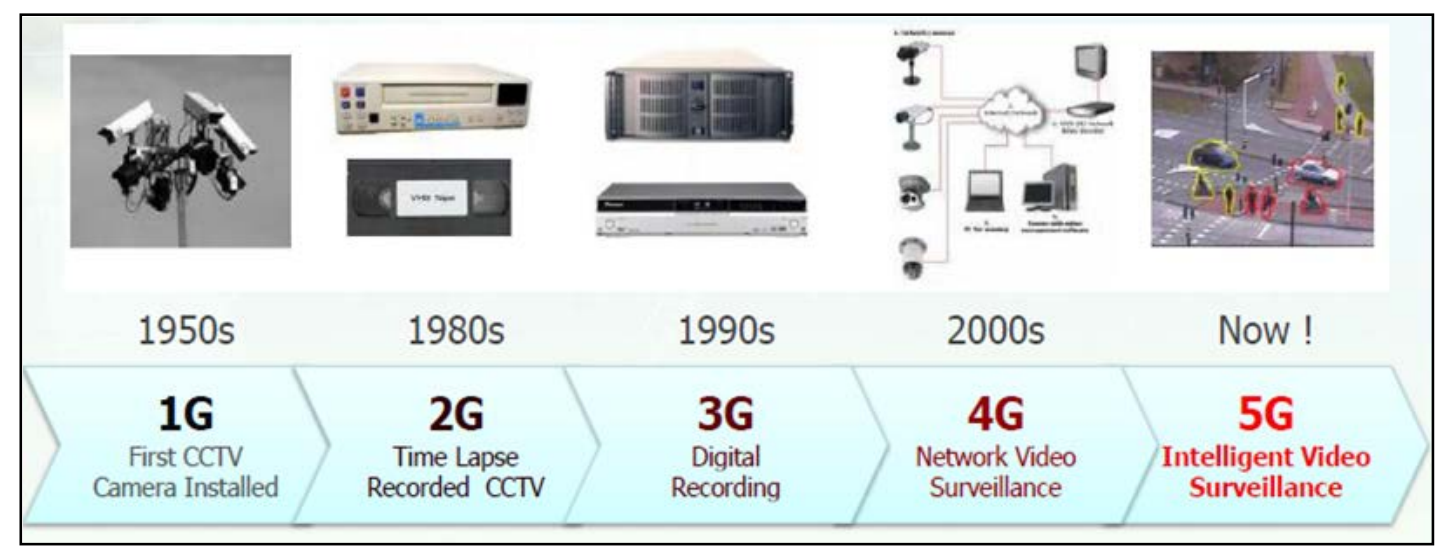

(※ Source: IMS research, 2007)

[Picture 1] Progress of CCTV 
That is, the intelligent CCTV is a system to inform special objects and behaviors by identifying them automatically through software program attached to the intelligent CCTV. It has benefits for not watching everything manually, but automatically. Therefore, it can be operated by minimum operators.

Current CCTV namely simple CCTV and intelligent CCTV comparison is as below:

Table 1. Simple CCTV VS Intelligent CCTV

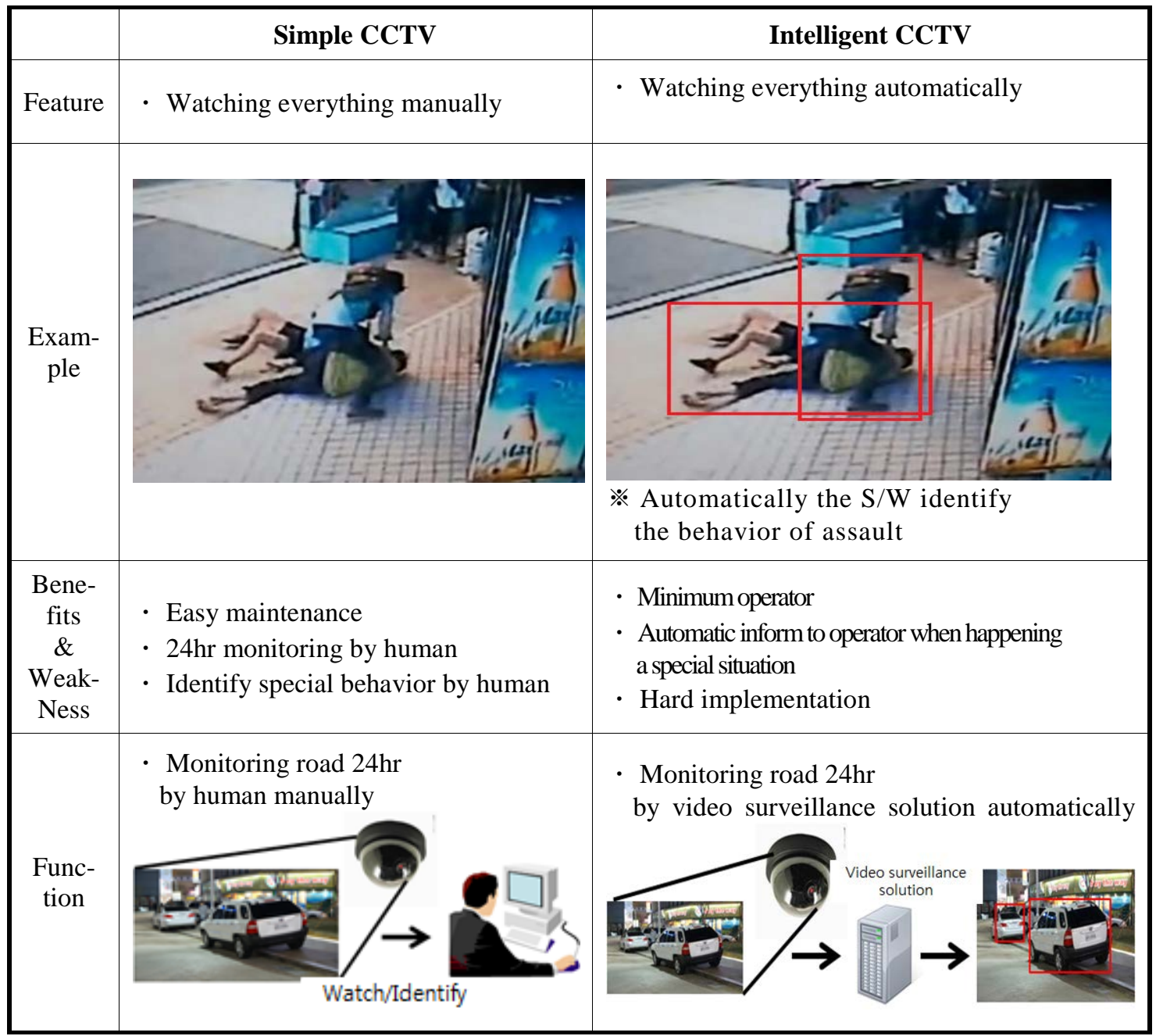

The intelligent CCTV shall be substituted for current 3G and 4G CCTV rapidly. That is, more than $45 \%$ of the video contents will be missed after someone watch video for $12 \mathrm{~min}$. continuously, which was studied by "Buyer beware". And also Sandia national lab found that when human watch video, only one video can be watched for 20 min. and important events shall be missed.

The USA appointed the intelligent CCTV technology as one of four major technologies in 2005. Because the intelligent CCTV technology will be expected for rapid market growth.

Therefore, the USA, UK and other counties implemented the intelligent CCTV test lab and made policy to enhance the performance of it by issuing certification for the excellent performance of intelligent CCTV. 
In Korea, the intelligent CCTV has been applied to video surveillance control center but false alarms have been happened frequently. So these systems are not applied to the center for 24 hours perfectly.

Hence, this paper reviews status of market and technology stage and deducts to enhance the performance of intelligent CCTV.

\section{Status of Market}

\subsection{Status of World Market}

Globally at video surveillance market shows that it picked up 9 billion dollars in 2010, it is expected 11.3 billion in 2012 and 14.4 billion in 2015. CARG is about $11.9 \%$.

Especially it is expected that area of analogue CCTV will grow slowly and IP based network CCTV quickly.

Among them, the intelligent CCTV market shows that it aggregates 0.2 billion dollars in 2010, 0.3 billion in 2012 and 0.6 billion in 2015.

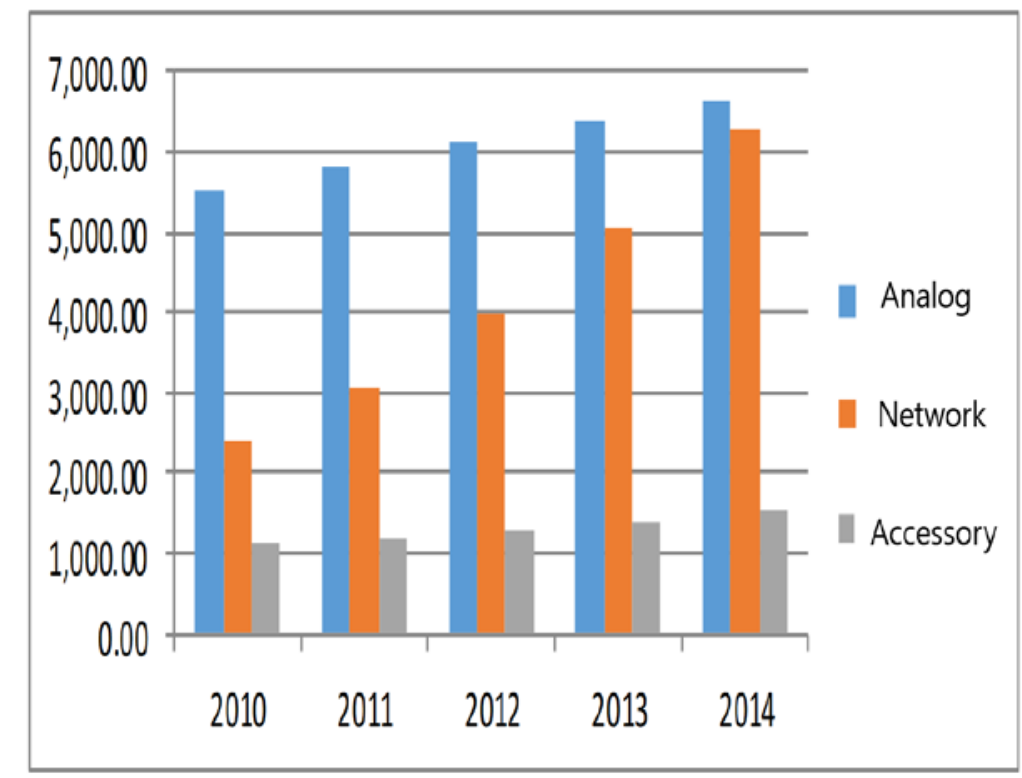

(※ Source: IMS research, 2011)

Figure 1. World Video Surveillance Market

\subsection{Status of Korean Market}

In case of Korean market, it is aggregated 1,856 billion won in 2010 and 2,118 billion won in 2012. Therefore CARG is about 7.1\%.

Especially, DVR market growth shows minus and IP based network CCTV shall be expected to be high growth.

Also, in the area of video surveillance software and intelligent solution intelligent based automatic system will be grown more than human based video surveillance software. 
Table 2. Status of Korean Market

(Monetary unit: 100 million wond)

\begin{tabular}{|c|c|c|c|c|c|}
\hline & 2009 & 2010 & 2011 & 2012 & CAGR \\
\hline \hline DVR & 5,938 & 5,819 & 5,550 & 5,680 & $-1.5 \%$ \\
\hline Camera & 6,708 & 7,332 & 8,030 & 8,450 & $8.0 \%$ \\
\hline IP-based facility & 1,031 & 1,260 & 1,560 & 1,850 & $21.5 \%$ \\
\hline Engine/Chipset & 650 & 780 & 960 & 1,140 & $20.6 \%$ \\
\hline Solution & 1,220 & 1,533 & 1,750 & 1,905 & $16.2 \%$ \\
\hline Accessory & 653 & 754 & 870 & 980 & $14.5 \%$ \\
\hline Etc. & 1,051 & 1,083 & 1,070 & 1,180 & $4.0 \%$ \\
\hline Total & 17,251 & 18,561 & 19,790 & 21,185 & $7.1 \%$ \\
\hline
\end{tabular}

(※ Source: KISA, 2012)

\section{Status of Technology}

The intelligent CCTV is the most developed in the USA and UK where diverse image data has been implemented for identifying and testing special behaviors to enhance the performance the intelligent CCTV solution.

\subsection{Status of America and Europe}

The study and research has been on the intelligent CCTV in the USA and EU countries. And the technology is tested and certificated.

Especially government of UK found i-LDS(Imagery Library for Detection Systems) a decade ago, implemented diverse image data and tested diverse behaviors of human and objects. And then excellent performance of the intelligent CCTV is given to certification of $\mathrm{i}$ LIDS mark.

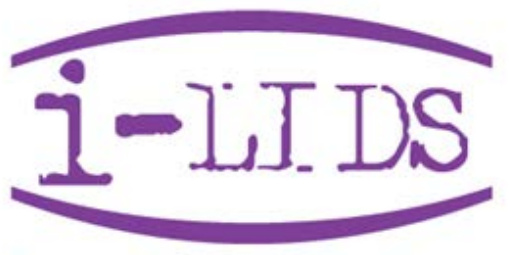

Imagery Library for Intelligent Detection Systems

\section{Figure 2. i-LIDS Certification Mark}

That is, in the USA and EU countries diverse behavioral image data has been implemented and these are given to many related companies. And these companies will use them and enhance the performance.

The image data implemented by each governments and academies is as follows. 
Table 3. Status of American and European image data for intelligent CCTV

\begin{tabular}{|c|c|c|c|c|}
\hline Name & Place & Size & Event & Screenshot \\
\hline PETS2002 & $\begin{array}{l}\text { Shopping } \\
\text { mall }\end{array}$ & $640 \times 240$ & $\begin{array}{l}\text { Man watching show } \\
\text { window }\end{array}$ & \\
\hline $\begin{array}{c}\text { PETS-ICVS } \\
2003\end{array}$ & $\begin{array}{l}\text { Meeting } \\
\text { room }\end{array}$ & $720 \times 576$ & $\begin{array}{l}\text { Man attending to } \\
\text { meeting }\end{array}$ & \\
\hline $\begin{array}{c}\text { VS-PETS } \\
2003 \text { - } \\
\text { INMOVE }\end{array}$ & $\begin{array}{l}\text { Soccer } \\
\text { field }\end{array}$ & $720 \times 576$ & Players & \\
\hline $\begin{array}{c}\text { PETS } \\
\text { ECCV2004- } \\
\text { CAVIAR }\end{array}$ & $\begin{array}{l}\text { Shopping } \\
\text { mall }\end{array}$ & $384 x 288$ & $\begin{array}{l}\text { Man moving, fighting } \\
\text { and etc. }\end{array}$ & \\
\hline $\begin{array}{c}\text { PETS2006 - } \\
\text { ISCAPS }\end{array}$ & Train station & $720 \times 576$ & Man walking & \\
\hline $\begin{array}{l}\text { PETS2007 - } \\
\text { REASON }\end{array}$ & Airport & $720 \times 576$ & Thief & \\
\hline $\begin{array}{l}\text { PETS2009 - } \\
\text { CROWD }\end{array}$ & Road & $768 \times 576$ & Moving & \\
\hline
\end{tabular}

\subsection{Status of Korea}

There are no cases to implement image data for the intelligent CCTV by Korean government. Only CCTV manufacturers got images from Internet or implemented images for their own in Korea.

Therefore, it is needed that official image data shall be implemented by authorized organization in Korea. 


\section{Methods to Enhance the Performance in Korea}

To enhance the performance of intelligent CCTV in Korea, diverse behavioral image data shall be implemented.

Therefore, this paper will suggest the methods to enhance it, which was derived from Korean intelligent CCTV experts committee in 2012.

\subsection{Scenario based Image Data Implementation}

Image data shall be implemented three kinds of type for purpose such as train, test and certificate. For train, the image data shall be provided to all companies and for test it shall be provided to the applicant who wants to receive certification.

For certificate, it shall not be opened and be used for only certificate the solution.

Table 4. Image Data Scenario for Intelligent CCTV

\begin{tabular}{|c|c|c|}
\hline Purpose & Scenario & Description \\
\hline \multirow{11}{*}{ Train } & Shadow & Identifying objects in circumstance of a shadow \\
\hline & Light & $\begin{array}{l}\text { Identifying objects in circumstance of diverse lights } \\
\text { (Streetlamp, camera flash, car headlight, etc.) }\end{array}$ \\
\hline & Low degree & Identifying objects in circumstance of no lights \\
\hline & $\begin{array}{l}\text { Camera } \\
\text { Shaking }\end{array}$ & $\begin{array}{l}\text { Identifying objects in circumstance of camera shaking because } \\
\text { of winds }\end{array}$ \\
\hline & Overlap & Identifying objects in circumstance of overlapping objects \\
\hline & Dynamic & Identifying objects in circumstance of background moving \\
\hline & Crowd & Identifying objects in circumstance of crowd \\
\hline & Color & Identifying objects in circumstance of diverse color clothes \\
\hline & Weather & Identifying objects in circumstance of weather changing \\
\hline & Business & $\begin{array}{l}\text { Identifying objects in circumstance of people in line, entering } \\
\text { gate, etc. }\end{array}$ \\
\hline & New tech. & Image data shoot by IR, 3D \\
\hline \multirow{3}{*}{ Test } & Wander & Identifying objects in circumstance of people wandering \\
\hline & Left & $\begin{array}{l}\text { Identifying objects in circumstance of things left for a long } \\
\text { time }\end{array}$ \\
\hline & Thief & Identifying objects in circumstance of thing thief \\
\hline
\end{tabular}




\begin{tabular}{|l|c|l|}
\hline \multirow{4}{*}{} & Tracking & Identifying and tracking objects \\
\cline { 2 - 3 } & Invasion & $\begin{array}{l}\text { Identifying objects in circumstance of people entering a gate } \\
\text { and climbing over the wall }\end{array}$ \\
\cline { 2 - 3 } & Behavior & Identifying behavior \\
\cline { 2 - 3 } & Crowd & Identifying objects in circumstance of crowd \\
\hline Certificate & Multi-event & Identifying multi behaviors and objects \\
\hline
\end{tabular}

\subsection{Diverse Specification Image Data Implementation}

The specification of image data for intelligent CCTV solution has no common standard in Korea. Therefore, it is needed that most used type of image data shall be implemented in Korea.

Table 5. Image Data Specification for Intelligent CCTV

\begin{tabular}{|c|c|l|}
\hline Item & Specification & \multicolumn{1}{|c|}{ Description } \\
\hline \hline Type & Video clip & Diverse format such as avi, mov, mpg and etc. \\
\hline Resolution & $\begin{array}{c}\text { Full HD } \\
(1920 x 1080)\end{array}$ & HD, D1, SD \\
\hline Frame & $30 f p s ~ 10 f p s$ & $\begin{array}{l}\text { - Shoot for 30fps } \\
\text { - Convert to 10 15fps }\end{array}$ \\
\hline Ground Truth & xml or txt & File name, lens, camera info., time, weather, event \\
\hline
\end{tabular}

\section{Future Plan}

As mentioned above, in order to enhance the performance of intelligent CCTV in Korea, diverse image data implementation shall be preceded and a certification to excellent products. Therefore, these are promoted and extend its business abroad.

Korean government and KISA (Korea Internet \& Security Agency) is planning to implement image data for the intelligent CCTV in 2013, and provide certification service in 2014. This will help to promote and develop the related industry and companies. 


\section{Acknowledgements}

This paper is written as a result of 'A study on establishment, testing and certification methods of intelligent CCTV behavior-based DB' which was funded by Ministry of Science, ICT \& Future Planning in Korea.

\section{References}

[1] IMS Research, The World Market for CCTV and Video Surveillance Equipment (2007).

[2] IMS Research, The World Market for CCTV and Video Surveillance Equipment (2011).

[3] KISA, National knowledge information security market status (2012).

[4] Home office science development branch, Image Library for Intelligent Detection System(i-LIDS) user guide (2012).

[5] KISA, A study on establishment, testing and certification methods of intelligent CCTV behavior-based DB (2012).

\section{Authors}

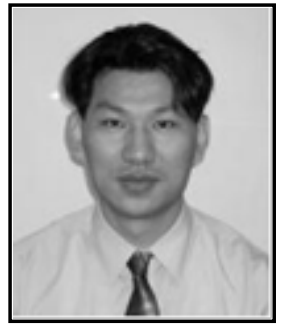

\section{Yong Wan Ju}

1997: HUFS in business management (bachelor's degree)

2002: Graduate School of Global Business, HUFS (master's degree)

2007: Soongsil University in Computer Science \& Engineering (doctor's degree)

1997-1999: National Information Society Agency (NIA)

2000-Current: Korea Internet \& Security Agency (KISA)



\section{Seung Jai Yi}

1997: HUFS in business management (bachelor's degree)

2001: Graduate School of MIS, HUFS (master's degree)

2000-Current: KISA 